\title{
Sexual Behavior of the Female Porcupine Hystrix africaeaustralis
}

\author{
D. J. Morris and R. J. van Aarde' \\ Mammal Research Institute, University of Pretoria, Pretoria 0002, South Africa
}

\begin{abstract}
Porcupines are sexually active throughout the estrous cycle, and sexual behavior is not affected by the reproductive status and hormonal milieu of females. Increased female--male interactions during estrus are the only indications of behavioral changes during estrus. The lack of aggression shown by females to known males as opposed to aggression shown to strange males, the greater interest shown by males toward certain females, and the superior breeding success of these females suggest a pair-bonding mating system. Limited changes in female receptivity throughout the cycle might be of importance in maintaining the pair-bond. (c) 1985 Academic Press, Inc.
\end{abstract}

Despite interest in the reproductive behavior of hystricomorph rodents (Bignami and Beach, 1968; Kleiman, 1970, 1971, 1974; Rood and Weir, 1970; Weir, 1971, 1973; Birke, 1981), little attention has been given to the African representatives of this suborder. Reproduction in Hystrix africaeaustralis, an Old World hystricomorph, is, as in other members of the order Hystricomorpha, characterized by a relatively long estrous cycle ( 30 days) and the presence of a vaginal closure membrane which is perforated during estrus and parturition (van Aarde, 1985).

Porcupines have previously been reported to live singly, in pairs, or in family groups (de Graaff, 1981; Smithers, 1983), the relationship between male and female porcupines remaining obscure. Consideration of literature relating to different hystricomorph rodents (e.g., the guinea pig Cavia porcellus: Young, Dempsey, Hagquist, and Boling, 1939; Birke, 1981; chinchilla Chinchilla lanigera: Bignami and Beach, 1968; acouchi $M y_{-}$ oprocta pratti: Kleiman, 1971) led to the postulation that female reproductive behavior, and especially receptivity, might change during the estrous cycle and that this should be related to the reproductive status of the female.

Hormones secreted by the female have been implicated in the regulation of sexual behavior of all studied species (Beach, 1976). In recent years

${ }^{1}$ To whom correspondence should be addressed. 
there has been increased interest in the relationship between hormones and reproductive behavior in wild animals. However, most studies have involved primate species (Bullock, Paris, and Goy, 1972; Nadler, Collins, Miller, and Graham, 1983; Shideler, Lindburg, and Lasley, 1983). The aim of the present study was to determine whether, and if so, how, the receptivity of the female porcupine changes during the estrous cycle. In this context, "receptivity" is intended to include attractivity, proceptivity, and receptivity as defined by Beach (1976).

\section{MATERIALS AND METHODS}

Subjects. Captive-born porcupines were housed in concrete enclosures with a floor space of $18.5 \mathrm{~m}^{2}$. Each enclosure had an indoor and outdoor area and was surrounded by a $1-\mathrm{m}$ brick wall. Porcupines were exposed to natural illumination and temperature and were fed daily on a mixture of fresh vegetables and fruit of the season. Fresh water was provided ad libitum. No bedding material and shelters such as nest boxes were provided. Individuals were identified by fitting color-coded stercolite collars around their necks. Details of the life histories of the seven females included in this investigation are represented in Table 1.

Porcupines were divided into five groups with Females A and B being housed in the same pen with Male A (intact) until 3 days before testing began, when he was removed to a separate pen. Females $C$ and $D$ were similarly housed with Male $\mathrm{C}$ (vasectomized) until 27 days before testing began, when he was removed to a separate pen. Male $F$ (intact) was separated from Female F 33 days before testing began, while Males E (vasectomized) and $\mathrm{G}$ (intact) remained with Females $\mathrm{E}$ and $\mathrm{G}$, respectively, throughout the experimental period.

The subjects included in this study can be divided thus:

(a) Three experimental groups where contact with males was limited to staged encounters. A "staged encounter" is defined as a 10-min test session in a testing arena when the behavior of the female in the presence of a male was recorded.

(b) Two control groups where each female (E and $G$ ) was continually in contact with a male. Behavior was also only recorded during staged encounters in a testing arena.

Behavioral procedure. The behavior of each female toward the male with whom she had been housed before the onset of the observational period was recorded at 5-day intervals over a 50-day period. Recording was more intensive, however, before and during estrus.

The test subject was herded from her pen into a $3.4 \times 2.4-\mathrm{m}$ testing arena which was washed with diluted acetic acid (3.0\%) before and after each testing session to minimize and standardize the effect(s) of animal odors on behavioral patterns. The male was then taken to the testing 
TABLE 1

Life History and Social Environment of Female Porcupines Included in the Experimental Group (E) and Control Group (C)

\begin{tabular}{|c|c|c|c|c|c|c|c|}
\hline \multicolumn{2}{|c|}{ Female } & \multirow{2}{*}{$\frac{\begin{array}{c}\mathrm{Age}^{a} \\
\text { (months) }\end{array}}{32}$} & \multirow{2}{*}{$\begin{array}{l}\begin{array}{c}\text { Reproductive } \\
\text { status }\end{array} \\
\text { Parous }\end{array}$} & \multirow{2}{*}{$\begin{array}{l}\text { No. of } \\
\text { litters }\end{array}$} & \multirow{2}{*}{$\begin{array}{c}\begin{array}{c}\text { Litter } \\
\text { size }\end{array} \\
2\end{array}$} & \multirow{2}{*}{$\begin{array}{c}\text { No. of days } \\
\text { since last estrus } \\
208 \\
\begin{array}{c}\text { (Lactating until } \\
4 / 23 / 82)\end{array}\end{array}$} & \multirow{2}{*}{$\frac{\text { Conspecifics present }^{b}}{2 \text { juvenile offspring, Female B }}$} \\
\hline A & (E) & & & & & & \\
\hline B & (E) & 31 & Nulliparous & - & - & 26 & 2 offspring of Female A; Female A \\
\hline $\mathrm{C}$ & (E) & 36 & Parous & 2 & $1+1$ & $\begin{array}{c}166 \\
\text { (Lactating until } \\
5 / 25 / 82)\end{array}$ & 2 female offspring; Female D \\
\hline $\mathrm{D}$ & (E) & 36 & Parous & Unknown & Unknown & 136 & 2 offspring of Female $C$; Female $C$ \\
\hline $\mathrm{E}$ & (C) & 36 & Nulliparous & - & - & 23 & Vasectomized Male E; Juvenile \\
\hline $\mathrm{F}$ & (E) & 15 & Parous & 1 & 1 & 34 & Single female juvenile offspring \\
\hline G & (C) & 22 & Nulliparous & - & - & 86 & Male G; juvenile male \\
\hline
\end{tabular}

a Age at beginning of the experimental period, $4 / 26 / 82$.

${ }^{b}$ Conspecifics present with the female over the entire experimental period, from $4 / 26 / 82$ to $6 / 14 / 82$. 
arena and Focal Animal Sampling (see Altmann, 1974) with the female as the focal subject, commenced as soon as both animals were in the arena. Clearly defined activities of the male toward the female were also recorded. The frequency of all and duration of most behavioral activities were recorded during a 10-min sampling period. Recorded activities including marking (both subjects), approaching (both subjects), contact (both subjects), presenting (both subjects), mounting, grooming (self-, allo-, or mutual), following, and exploring.

Behavioral definitions.

Marking. Recorded whenever the subject dragged its perineal region along the surface of the testing arena or on a brick placed in the center of the arena. Marking was often accompanied by urination.

Approaching. Recorded whenever one of the subjects purposefully approached to within approximately $0.5 \mathrm{~m}$ of the other.

Contact. Recorded whenever one subject made physical contact with the other. Contact usually involved sniffing and investigatory behavior and was often succeeded by allo- or mutual grooming.

Grooming. Involved licking the head, flanks, or forepaws and was classified as either self-, allo-, or mutual grooming.

Following. One individual walking behind (within approximately $30 \mathrm{~cm}$ ) the other. (This behavior often resulted in the male touching the female's tail with his nose. thereby eliciting lordosis in the female).

Presenting. Recorded when either animal exhibited lordosis. This was characterized by an immobile posture with the erection of the quills and flattening of the back so that the body was close to the floor with the rump and tail raised (Fig. 1).

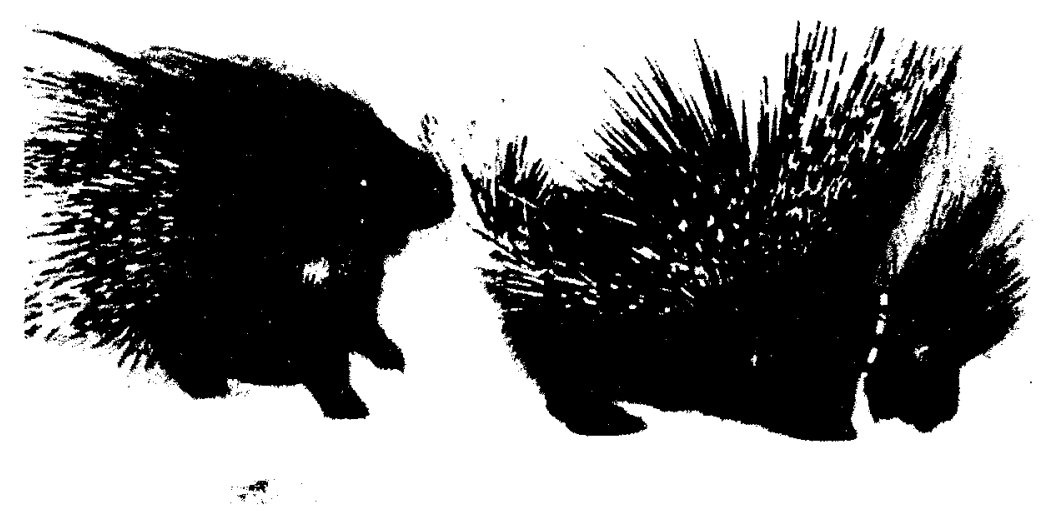

FIG. 1. Female porcupine exhibiting lordosis in response to tactile stimulation from the male. 
Mounting. The male standing bipedally and resting his forepaws on the female's back (Fig. 2). Thrusting occurred during intromission.

Exploring. Any activity, besides those previously described, and excluding sitting motionless or resting. This behavior usually took the form of investigating the test arena.

Sexual behavior is here defined as all behavioral activities of the female or male toward the male and female, respectively, and includes approach, contact, presenting, and mounting. Copulatory behavior included all of these except that mounting was followed by copulation.

Determination of plasma levels of steroid hormones. Blood samples $(5.0 \mathrm{ml})$ were collected from immobilized females through cardiac puncture on the day following the behavioral test session. Females were immobilized through an intramuscular injection of a mixture of xylazine hydrochloride (Rompun; Bayer, Leverkusen, F.R.G.) and ketamine hydrochloride (Ketalar; Parke-Davis Laboratories (Pty) Ltd., Isando, S. Africa) at a mean dose rate of $1.6 \pm 0.29 \mathrm{mg} / \mathrm{kg}(n=57)$ Rompun and $5.5 \pm 0.64$ $\mathrm{mg} / \mathrm{kg}(n=61) \mathrm{Ketalar}$

Plasma fractions collected from heparinized centrifuged blood samples were stored at $-20^{\circ} \mathrm{C}$ within $1 \mathrm{~h}$ of sampling until assayed for progesterone and estradiol- $17 \beta$ levels.

The procedure used to measure plasma levels of progesterone was similar to that of Haresign, Foster, Haynes, Crighton, and Lamming (1975) using antiserum raised in a goat to progesterone-11-succinyl-bovine serum albumin as described by Furr (1973) and supplied by Specific Antisera Ltd. (Wilmslow, U.K.)

The specificity of the antiserum was described by Furr (1973). Sensitivity

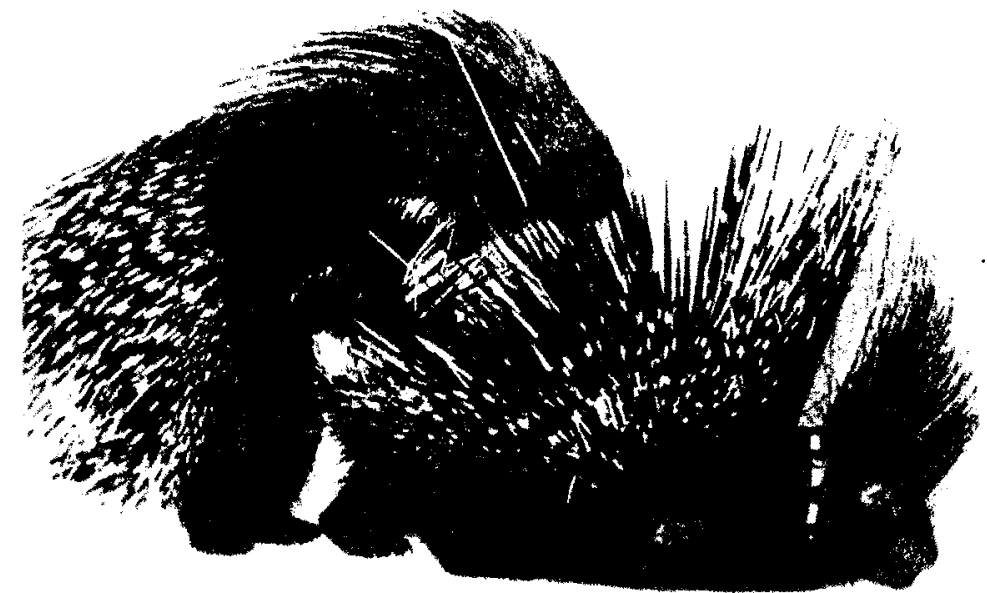

Fig. 2. The mounting posture in the porcupine Hystrix africaeatstralis. 
defined as twice the standard deviation of blank values ranged from 0.16 to $0.93 \mathrm{ng} / \mathrm{ml}(\bar{x}=0.49 \pm 0.21 ; n=7)$. Intraassay coefficient of variation based on 20 duplicate samples was 9.0 and $14.0 \%$ for the ranges 40 to 60 and 60 to $80 \%$ bound, respectively. Interassay variation based on a plasma sample included in all assays containing $2.4 \pm 0.13 \mathrm{ng} / \mathrm{ml}$ was $14.2 \%$. Addition of 125 and $500 \mathrm{pg}$ progesterone to a plasma pool included in six assays gave recoveries of $94.0 \pm 4.8$ and $109.0 \pm 4.2 \%$, respectively.

The protocol adapted to determine plasma levels of unconjugated estradiol-17 $\beta$ was similar to that described by Abraham (1976). Steroids were, however, not purified and separated by chromatography after extraction. The antiserum supplied by the Department of Chemical Pathology, University of Cape Town, South Africa, was highly specific, and crossreactions with other steroids were less than $0.01 \%$. The sensitivity of the assays varied from 3.7 to $15.8 \mathrm{pg} / \mathrm{ml}(\bar{x}=11.7 \pm 3.92 ; n=6)$. Intra- and interassay coefficients of variation were 2.4 and $16.2 \%$, respectively, and extraction efficiency varied from 85.1 to $96.8 \%$. The amount of estradiol-17 $\beta$ added to male plasma pools did not differ significantly $(t=0.25, P(15)<0.001)$ from the amount measured.

Determination of estrous cycle length. The length of the estrous cycle was considered equivalent to the interval between the perforation of the vaginal closure membrane at one estrus to the day before the onset of the following estrus (Weir, 1974). The condition of the vaginal closure membrane was therefore recorded whenever a female was under anesthesia.

\section{RESULTS}

\section{Characteristics of the Estrous Cycle}

Estrus, as suggested by the opening of the vaginal closure membrane, occurred in all but one (Female D) of the females during the experimental period. Only four of the eight periods of estrus were associated with a surge in estradiol-17 $\beta$ secretion, and three of these were followed by detectable increases in plasma progesterone levels. Two periods of estrus not associated with an increase in estradiol-17 $\beta$ levels were followed by increased progesterone secretions.

The length of the estrous cycle varied from 25 to 35 days $(\bar{x}=28.4$ $\pm 3.86 \mathrm{SD} ; n=5$ ) with the length of the luteal phase varying from 11 to 26 days $(\vec{x}=19.5 \pm 7.2 ; n=4)$ and that of the follicular phase from 4 to 8 days $(n=2)$.

\section{Behavior of the Fermale during the Estrous Cycle}

In general, the onset of estrus was not apparent from behavioral observations alone. The frequency of occurrence of various components of sexual behavior did change during the cycle, but no definite trend in behavior patterns and regularity of timing could be identified.

The total amount of sexual behavior (sum of frequencies of different 
components of sexual behavior) displayed by a female was relatively constant and apparently not affected by her hormonal status. However, the time spent on sexual activities by experimental Female A (represented as a percentage of the total observation time) changed during the cycle (Fig. 3) with the duration of contact, presentation, and mounting all peaking on Day 0. No definite pattern existed for experimental Females $\mathrm{B}$ and C (Fig. 3) and the control females (Fig. 4). Receptivity scores ("lordosis" or copulatory quotients; see Beach, 1943) did not change during estrus, suggesting that female receptivity remained relatively constant throughout the cycle.

\section{Sexual and Copulatory Behavior}

Females in the experimental groups initiated most of the sexual behavior while males initiated most sexual behavior in the control groups. Initiation of sexual behavior in the experimental groups commenced most of the time with the female approaching the male, followed by mutual grooming and, when not ignored by the male, by presentation (lordosis). Presentation was, however, sometimes initiated by the male touching the posterior region of the female with his nose. This was then followed by the male either ignoring the female or mounting the female, with intromission only occurring during estrus. The sequence of events occurring during sexual behavior could be interrupted at all stages by either of the two participants breaking contact by moving away from the other.

A copulation observed under experimental conditions lasted $154 \mathrm{sec}$ with 38 thrusts followed by ejaculation, being terminated by the male dismounting. Receptivity lasted approximately $9 \mathrm{hr}$. The copulatory plug was expelled $48 \mathrm{hr}$ later.

Experimental females approach males significantly more frequently than being approached by their males $\left(\chi^{2}=43.4 ; P(2)<0.5\right)$. Females also marked more frequently than their male counterparts $\left(\chi^{2}=44.4\right.$; $P(2)<0.5)$. In contrast, control females were more frequently approached by their males which also marked more frequently than the females except when control females were in estrus. Limited sample sizes precluded meaningful statistical comparisons.

The behavior of a specific male toward the females to which he had been habituated before the onset of the observation period also differed markedly: Male A approached Female A 5.6 times as often as he approached Female B, with Female A approaching Male A 1.2 times as often as Female $B$ did. The ratio of the number of male: female approaches observed throughout the study period suggests that this male had a preference for Female A.

\section{DISCUSSION}

Components of sexual behavior occurred throughout the estrous cycle and appear not to be affected by the reproductive status and hormonal 

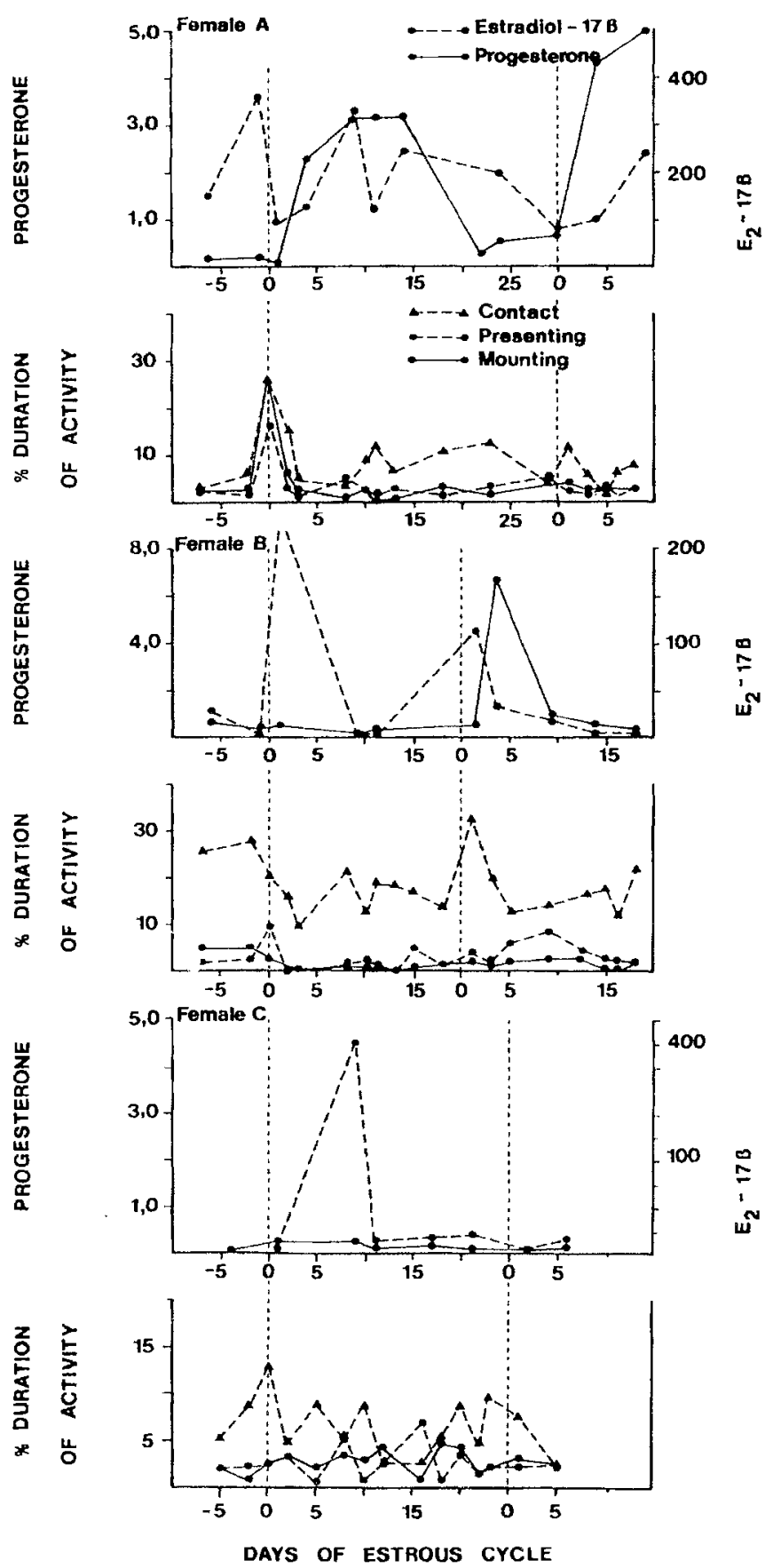

Fig. 3. Circulating levels of plasma progesterone $(\mathrm{ng} / \mathrm{ml})$ and estradiol- $17 \beta(\mathrm{pg} / \mathrm{ml})$, and duration (percentage of total observation time) of reproductive activities in experimental female porcupines throughout the experimental period. Day 0 denotes the day when vaginal opening was first observed, i.e., estrus. 


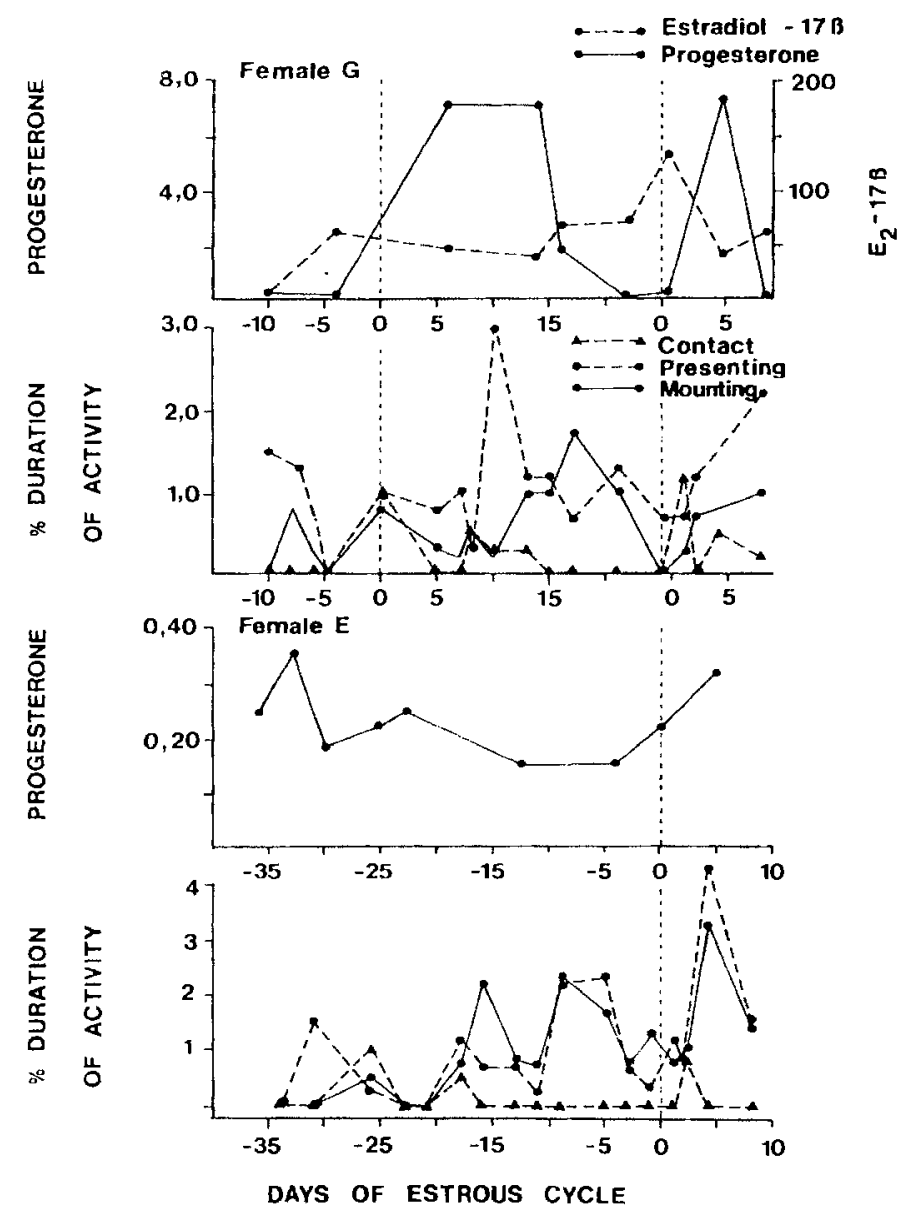

FIG, 4. Circulating levels of plasma progesterone $(\mathrm{ng} / \mathrm{ml})$ and estradiol $17 \beta(\mathrm{pg} / \mathrm{ml})$, and duration (percentage of total observation time) of reproductive activities in control female porcupines throughout the experimental period. Day 0 denotes the day when vaginal opening was first observed, i.e., estrus. (Estradiol-17 $\beta$ was below the level of detection in all samples assayed for Female E.)

milieu of the female porcupine. This is contrary to observations on some hystricomorph rodents, for example, the guinea pig Cavia porcellus in which obvious changes in sexual behavior characterize the estrous period (Birke, 1981). However, unpredictable behavior of hystricomorph females during estrus has previously been noted (e.g., chinchilla) (Bignami and Beach, 1968).

The observation that females spend more time in contact with males during estrus and the increased female-male interaction during estrus are the only indications of behavioral changes during estrus. Female guinea pigs are also known to spend more time interacting with males during pro-estrus (Birke, 1981). 
Differences between sexual and copulatory behaviors in the porcupine are subtle. They are associated with intromission which can only occur at estrus when the vaginal membrane is perforated. A close parallel to our distinction between sexual and copulatory behavior has been illustrated for the pigtale macaque Macaca nemestrina (Bullock et al., 1972) where patterns of sexual behavior changed little during the menstrual cycle, yet the occurrence of ejaculation and sex skin swelling were coincident.

The high frequencies at which experimental females and males approached and contacted each other is probably an artifact of experimental conditions; isolation between test sessions would conceivably stimulate intersexual interest. Control animals which were kept in the same enclosure throughout the study period also approached and contacted each other during most test sessions throughout the study period although at a much lower frequency than the experimental animals. The only change in this behavior during the estrous cycle was the increase in approaches made toward the male by a control female (Female G) during estrus. This probably reflects typical behavior under natural conditions with the female showing more interest in the male during estrus than met-estrus.

Kleiman (1974) states that a high level of aggression is common in reproductively active but nonreceptive hystricomorph females. As a result of the morphological characteristics and the presence of sharp posteriorly directed quills, appeasement and solicitation may be considered vital prerequisites for mounting in the Cape porcupine. Although female porcupines included in this study were aggressive towards strange males, they never exhibited any form of aggression (i.e., tail rattling, food stamping, or quill erection) towards males with whom they had cohabited before or during the period of observation. Appeasement was therefore not required, and the absence of a complicated courtship ritual in male porcupines may thus be ascribed to a lack of female aggression. Since aggression could prove discomforting to the male, which actively participates in the rearing of the young (van Aarde, 1984), lack of aggression towards a known male will conceivably have a selective advantage for the female.

The incidence of aggression, or lack thereof, in the porcupine during staged encounters is reminiscent of the situation described by Getz, Carter, and Gavish (1981) for the prairie vole Microtus achrogaster. In laboratory encounters, both male and female voles from breeding pairs tended to show relatively high levels of aggression toward unfamiliar animals of the opposite sex. In contrast, aggression was rarely observed between members of established breeding pairs (Getz et al., 1981). These results were used as partial evidence for pair-bonding in the prairie vole, and the similar evidence available for the porcupine may also be indicative of pair-bonding.

Kleiman (1971) reported that when several adults of both sexes of 
green acouchis are housed together, individual males and females tend to form pair-bonds. Kleiman (1971) also found that during observations of one group of six acouchis (three females, three males), each male directed most of his courting activity toward one female. A similar trend is apparent in the porcupine; the greater number of approaches directed by Male $A$ to Female $A$ than to Female $B$, irrespective of the estral status of the female, illustrates this point. Moreover, comparing breeding success of these two females, Female A conceived and brought to term two offspring, whereas Female B, although sexually mature, was still nulliparous at the end of the study. Similarly, Female $C$ conceived twice and produced two offspring, yet Female D, although parous, has never conceived while housed with Female C and Male B. Again, this phenomenon in the porcupine can be likened to that in the green acouchi where young were conceived more quickly, brought to term, reared, and weaned when animals were housed in pairs (Kleiman, 1971).

Sexual behavior and various other interactive activities have frequently been identified as strengthening the pair-bond (Erickson, 1978), and this is a possible explanation for the persistence of such activities throughout the estrous cycle of the porcupine.

Kleiman (1974) suggests that the shortness of the receptive period in most hystricomorph rodents could explain the persistent courtship of the male and his increased attention given to the female during proestrus. Lisk (1978) states that the maximum duration of sexual heat for all species examined is $15 \%$ of the estrous cycle length. In sheep, with an estrous cycle of 16 days, sexual behavior lasts for approximately $24 \mathrm{hr}$. In the guinea pig, with the same cycle length, estrus lasts for 8-10 hr. Yet in the porcupine, with a cycle length of 30 days, behavioral estrus (or sexual heat) lasts for approximately $9 \mathrm{hr}(1.23 \%$ of the cycle length). This short period of receptivity of the female could also explain the maintenance of sexual activity on the part of the male throughout the estrous cycle.

\section{CONCLUSION}

Sexual activity occurs throughout the estrous cycle and therefore does not reflect the hormonal status of the female porcupine.

A distinction can be made between sexual behavior and copulatory behavior, with the latter occurring only during estrus when the vaginal closure membrane of the female is perforated. Although some components of copulatory behavior occur throughout the cycle, complete copulations with intromission occur only during estrus. The only indications of increased receptivity of the female during estrus are increased female:male approaches and an increased duration of female:male contact.

There is considerable evidence indicating that in captivity porcupines form pair-bonds. These include (i) the lack of aggression shown by females to known males (as opposed to the aggression shown to strange males), 
(ii) the greater interest shown by males towards certain females, and (iii) the superior breeding success of the females referred to in (ii) above.

Whether pair-bonding is the operative mating system in the wild is unknown, yet their reproductive behavior suggests that this might be the case.

\section{ACKNOWLEDGMENTS}

One of us, D. J. Morris, was a recipient of a Council for Scientific and Industrial Research bursary. We gratefully acknowledge the assistance provided by Denvin Majola.

\section{REFERENCES}

Abraham, E. G. (1976). Radioimmunoassay of oestradiol-17 $\beta$ in plasma. In H. Breuer, D. Hamel, and H. L. Krüskemper (Eds.), Methods of Hormone Analysis. George Thieme Verlag, Stuttgart.

Altmann, J. (1974). Observational study of behaviour: Sampling methods. Behaviour 49, $227-267$.

Beach, F. A. (1943). Effects of injury to the cerebral cortex upon the display of masculine and feminine mating behaviour by female rats. J. Comp. Psychol. 36, 169-198.

Beach, F. A. (1976). Sexual attractivity, proceptivity, and receptivity in female mammals. Horm. Behav. 7, 105-138.

Bignami, G., and Beach, F. A. (1968). Mating behaviour in the chinchilla. Anim. Behav. $16,45-53$.

Birke, L. I. A. (1981). Some behavioural changes associated with the guinea-pig oestrous cycle. Z. Tierpsychol. 55, 79-89.

Bullock, D. W., Paris, C. A., and Goy, R. W. (1972). Sexual behaviour, swelling of the sex skin and plasma progesterone in the pigtail macaque. J. Reprod. Feril. 31, 225236.

de Graaff, G. (1981). The Rodents of Southern Africa. Butterworths, Pretoria, S. Africa.

Erickson, C. J. (1978). Sexual affiliation in animals: Pair bonds and reproductive strategies. In J. B. Hutchinson (Ed.), Biological Determinants of Sexual Behaviour, pp. 697726. Wiley, Chichester.

Furr, B. J. A. (1973). Radioimmunoassay of progesterone in peripheral plasma of the domestic fowl in various physiological states and in follicular venous plasma. Acta Endocrinol. (Copenhagen) 72, 89-100.

Getz, L. L., Carter, C. S., and Gavish, L. (1981). The mating system of the prairie vole, Microtus achrogaster: Field and laboratory evidence for pair-bonding. Behav. Ecol. Sociobiol. 8, 189-194.

Haresign, W., Foster, J. P., Haynes, N. B., Crighton, D. B., and Lamming, G. E. (1975). Progesterone levels following treatment of seasonally anoestrous ewes with synthetic LH-releasing hormone. J. Reprod. Fertil. 43, 269-279.

Kleiman, D. G. (1970). Reproduction in the female green acouchi, Myoprocta pratti Pocock. J. Reprod. Fertil. 23, 55-65.

Kleiman, D. G. (1971). The courtship and copulatory behaviour of the green acouchi, Myoprocta pratti. Z. Tierpsychol. 29, 259-278.

Kleiman, D. G. (1974). Patterns of behaviour in hystricomorph rodents. Symp. Zool. Soc. London 34, 171-209.

Lisk, R. D. (1978). The regulation of sexual 'heat.' In J. B. Hutchinson (Ed.), Biological Determinants of Sexual Behaviour, pp. 425-466. Wiley, Chichester.

Nadler, R. D., Collins, D. C., Miller, L. C., and Graham, C. E. (1983). Menstrual cycle patterns of hormones and sexual behaviour in gorillas. Horm. Behav. 17, 1-17. 
Rood, J. P., and Weir, Barbara J. (1970). Reproduction in female wild guinea-pigs. $J$. Reprod. Fertil. 23, 393-409.

Shideler, S. E., Lindburg, D. G., and Lasley, B. L. (1983). Estrogen behaviour correlates in the reproductive physiology and behaviour of the ruffed lemur (Lemur variegatus). Horm. Behav. 17, 249-263.

Smithers, R. H. N. (1983). The Mammals of the Southern African Subregion, pp. 186I88. University of Pretoria, Pretoria, S. Africa.

van Aarde, R. J. (1984). Reproduction in the porcupine Hystrix africaeaustralis Peters. D.Sc. thesis. University of Pretoria, Pretoria, South Africa.

van Aarde, R. J. (1985). Reproduction in captive female Cape porcupines (Hystrix africaeaustralis). J. Reprod. Fertil., 75, 577-582.

Weir, Barbara J. (1971). The evocation of oestrus in the cuis, Galea musteloides. J. Reprod. Fertil. 26, 405-408.

Weir, Barbara J. (1973). The induction of ovulation and oestrus in the chinchilla. J. Reprod. Fertil. 33, 61-68.

Weir, Barbara J. (1974). Reproductive characteristics of hystricomorph rodents. Symp. Zool. Soc. London 34, 265-301.

Young, W. C., Dempsey, E. W., Hagquist, C. W., and Boling, J. L. (1939). Sexual behaviour and sexual receptivity in the female guinea-pig. J. Comp. Psychol. 27, 4767. 